\title{
Electronic properties of polypyrrole/polyindene composite/metal junctions
}

\author{
A. Bozkurt ${ }^{\text {a }}$, C. Ercelebi ${ }^{b}$, L. Toppare ${ }^{\text {c,* }}$ \\ a Department of Chemistry, Middle East Technical University, 06531 Ankara, Turkey \\ - Department of Physics, Middle East Technical University, 06531 Ankara, Turkey \\ 'Department of Chemistry, Bilkent University, 06533 Ankara, Turkey \\ Received 16 April 1996; accepted 23 December 1996
}

\begin{abstract}
Junction properties between conducting polymer composites of polypyrrole/polyindene (PPy/PIn) with different conductivities and metals like Pt, Au, Al and In have been investigated. Rectifying junctions were observed for low work function metals, In and Al; however, high work function metals, $\mathrm{Pt}$ and $\mathrm{Au}$, were observed to form ohmic contacts to PPy/PIn composite in the sandwich geometry. The rectifying behavior of the metal/composite/Pt junctions improved when the conductivity of the composite was decreased from 1 to $0.01 \mathrm{~S} / \mathrm{cm}$. Using the ideal Schottky theory various junction parameters have been determined. All planar junctions were ohmic regardless of the conductivities of the samples.
\end{abstract}

Keywords: Electronic properties; Polypyrrole; Polyindene; Composite/metal junctions

\section{Introduction}

The attractiveness of conducting polymers, especially those produced from heterocyclic monomers, have created enormous interest in the past few decades due to their stability and low cost. However, they have poor mechanical properties and processibility. Due to this reason, considerable progress has begun in improving their mechanical properties. These improvements have been achieved by a method of blending with conventional polymers [1-9].

Electrically conductive polymers such as polyacetylene, polypyrrole and polythiophene have found promising applications in electronic devices since the 1960s. In particular, polypyrrole and polypyrrole/poly ( $N$-methylpyrrole) are being studied as active materials in electronic devices and it was reported that these materials form Schottky contacts with $\mathrm{Al}$ and $\mathrm{In}[10-13]$.

In this present work, a new method for the preparation of polypyrrole/polyindene (PPy/PIn) composite/metal junctions is suggested and the rectifying effects of metals $/ \mathrm{com}-$ posite Schottky barrier diodes are discussed using currentvoltage $(I-V)$ and capacitance-voltage $(C-V)$ characteristics. The synthesis and characterization of the composites with different methods were given in a previous work [14].

\footnotetext{
* Corresponding author.
}

\section{Experimental}

Composite films of PPy/PIn were electrochemically prepared by using two different sets of experiments. In the first, $0.1 \mathrm{M}$ indene monomer in acetonitrile was used for the electrochemical polymerization of indene on a platinum electrode at $2.0 \mathrm{~V}$ versus $\mathrm{Ag}^{0} / \mathrm{Ag}^{+}$at room temperature. Then electrochemical polymerization of pyrrole onto a polyindene-coated electrode at a constant potential of $1.0 \mathrm{~V}$ versus $\mathrm{Ag}^{0} / \mathrm{Ag}^{+}$in a different cell was carried out where the pyrrole concentration was $0.05 \mathrm{M}$.

In the second set the composite films were prepared by the electrooxidation of indene at a constant potential of $2.0 \mathrm{~V}$ versus $\mathrm{Ag} / \mathrm{Ag}^{+}\left(10^{-2} \mathrm{M}\right)$ in a cell containing $0.05 \mathrm{M}$ indene. The electrode here was PPy which was previously prepared at a constant potential of $1.0 \mathrm{~V}$ versus $\mathrm{Ag}^{0} / \mathrm{Ag}^{+}$ $\left(10^{-2} \mathrm{M}\right)$ on a platinum electrode in a different cell containing $0.05 \mathrm{M}$ pyrrole monomer.

Electrochemical polymerizations were carried out in a three-compartment cell equipped with platinum foils $\left(1 \mathrm{~cm}^{2}\right)$ as the working and auxiliary electrodes. The solvent-electrolyte was acetonitrile-tetrabutylammonium tetrafluoroborate (TBAFB).

For both systems, films with different surface conductivities were produced by varying the electrolyte concentration 

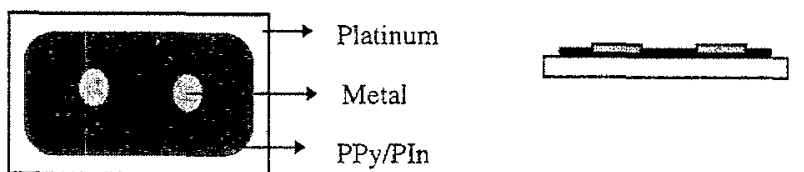

Fig. 1. Configuration of $\mathrm{Pt} /$ composite/metal junctions: top view and cross section.

from 0.1 to $0.01 \mathrm{M}$. Electrical conductivities of samples were measured via the standard four-probe technique.

The evaporation of metals for the contact formation was done on composite ( $\mathrm{PPy} / \mathrm{PIn}$ )-coated Pt electrodes by using the Nanotech (thin film) evaporator system. A point mask was used during vacuum deposition of different metals. Au, $\mathrm{Al}$ and In were evaporated on the surfaces of the composite films which were synthesized by using both systems. The device structure is illustrated in Fig. 1.

The composite films were about $10 \mu \mathrm{m}$ thick and the contact area was $0.03 \mathrm{~cm}^{2}$. In order to measure forward and reverse $I-V$ characteristics of the devices, current was passed between the two contacts by using a Keithley model 225 constant-current source. The voltage drop across the device was measured by using a Keithley model 614 digital electrometer. $I-V$ measurements were carried out at room temperature in a dark box.

The room-temperature $C-V$ measurements were made using a $1 \mathrm{MHz}$ capacitance meter of the model DLS-82 semitrap DLTS (deep level transient spectroscopy) system.

\section{Results and discussion}

For both the first and the second sets of experiments the electrochemically produced composites (PPy/PIn) yielded homogeneous films, at least in terms of conductivity. It was demonstrated that for both systems the conductivities of the films were not greatly affected by the percolation composition, after $80 \%$ PPy content [14]. The aim of the insulating matrix in the composite was to solve the pinhole problem almost completely and obtain good surface morphology without changing the properties of conducting PPy.

The bulk conductivity of the films has major importance when producing a Schottky contact. This property was controlled by the low charge density which is associated with the low doping of polymer [13]. The production of the films with conductivities ranging from 1 to $0.01 \mathrm{~S} / \mathrm{cm}$ was carried out by varying the concentration of dopant (TBAFB). We also showed that, as the conductivities of the films lowered, better rectifying characteristics were observed.

Before deposition of the metals as a top electrode, the samples were heat treated (curing, $90^{\circ} \mathrm{C}$ ) under vacuum in order to prepare the surface for the production of reliable and stable contacts and to remove water, if any, from the composite films.

The $I-V$ characteristics of p-type PPy in the PPy/PIn composite films were expected to show ohmic behaviors between high work function metals such as $\mathrm{Pt}\left(\phi_{\mathrm{Pt}}=5.65 \mathrm{eV}\right)$ and $\mathrm{Au}$
$\left(\phi_{\mathrm{Au}}=5.1 \mathrm{eV}\right)$. Fig. 2 shows the typical $I-V$ characteristic of the Au-PPy/PIn-Pt sandwich structure. Current varies linearly with the applied voltage and the slope of $\log I-\log V$ variation is almost unity, which indicates the ohmic behavior of the contacts. This ohmic nature of the contacts was checked by reversing the polarity of the applied voltage and the $I-V$ characteristics were observed to remain essentially the same with the reversal of applied bias. The forward voltage bias corresponds to a negative voltage at metals (front contact) with respect to $\mathrm{Pt}$ back contact. The junction properties of Au-PPy/PIn-Pt structure were observed to be ohmic for both systems regardless of their conductivities.

The interface between the PPy/PIn composite and low work function metals such as In $\left(\phi_{\mathrm{In}}=4.12 \mathrm{eV}\right)$ and $\mathrm{AI}$ $\left(\phi_{\mathrm{A} 1}=4.28 \mathrm{eV}\right.$ ) was expected to make rectifying contact. $\mathrm{A} 1 / \mathrm{In} /$ composite/Pt junctions have been investigated for different film conductivities such as $1,0.1$ and $0.01 \mathrm{~S} / \mathrm{cm}$. The $I-V$ characteristics of these junctions were observed to be nonohmic and asymmetrical leading to a rectifying behavior. The results showed that the junctions formed from the composite films synthesized by the second system with conductivities $1-0.1 \mathrm{~S} / \mathrm{cm}$ are more rectifying than those obtained by the first system. The better rectifying behavior observed for the metal/composite junctions constructed via the second method even though the films are highly conducting (1-0.1 $\mathrm{S} / \mathrm{cm})$ is attributed to the dense PIn insulating phase on the solution side of the composite films which was elucidated by the scanning electron microscopy (SEM) photographs [14]. Figs. 3 and 4 illustrate the typical $I-V$ characteristics of In/ composite/ $\mathrm{Pt}$ junctions prepared by the first and second systems $(\sigma=1 \mathrm{~S} / \mathrm{cm})$, respectively.

The composite films which have conductivities about 0.1 $\mathrm{S} / \mathrm{cm}$ lead to better rectifying behavior as demonstrated in Fig. 5 (a) and (b) for In/composite and Al/composite junctions, respectively, prepared by the second system. Metal/ conducting-polymer junctions have been investigated previously and it was reported that, for the films with high

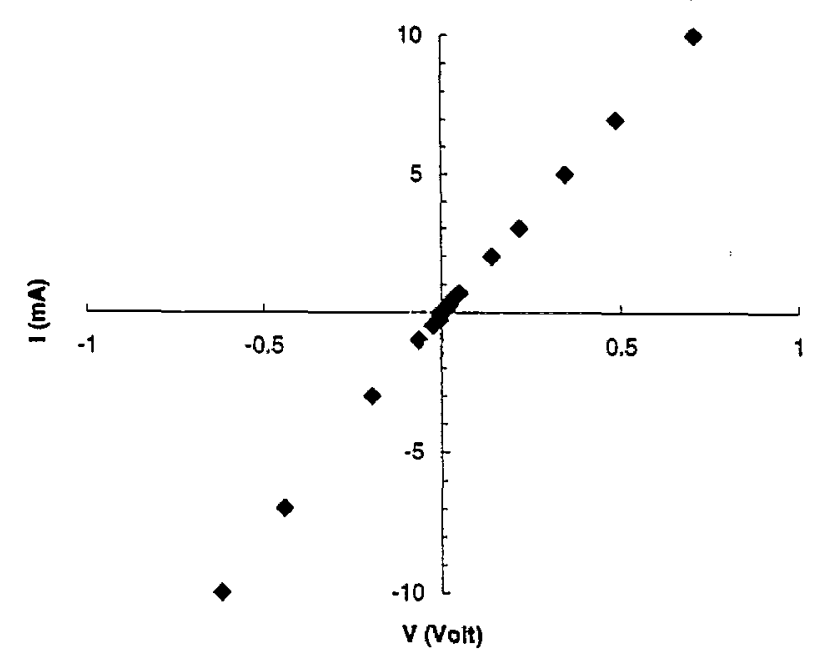

Fig. 2. $I-V$ characteristic of $\mathrm{Pt} /$ composite/Au sandwich junction $(\sigma=$ $0.8 \mathrm{~S} / \mathrm{cm}$ ) 


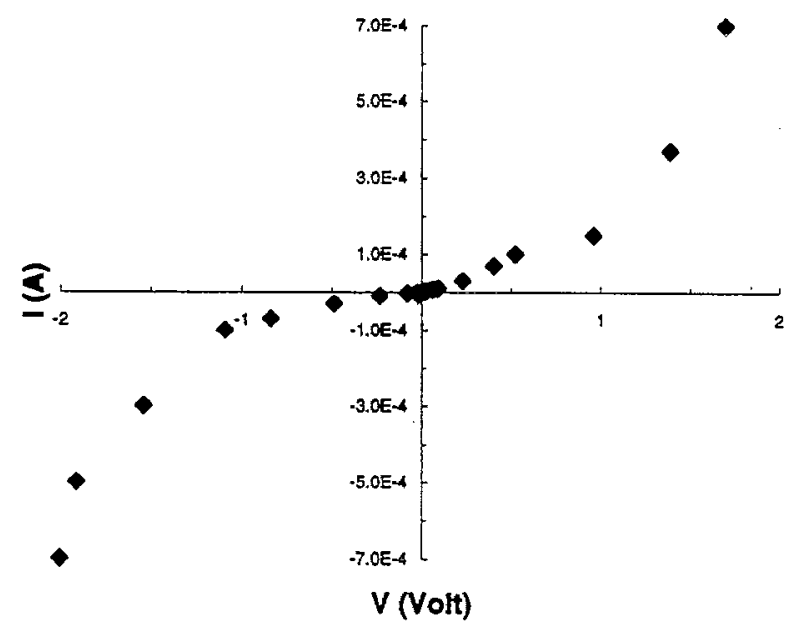

Fig. 3. $I-V$ characteristic of $I n /$ composite/Pt junction (first system, $\sigma \approx$ $1 \mathrm{~S} / \mathrm{cm})$

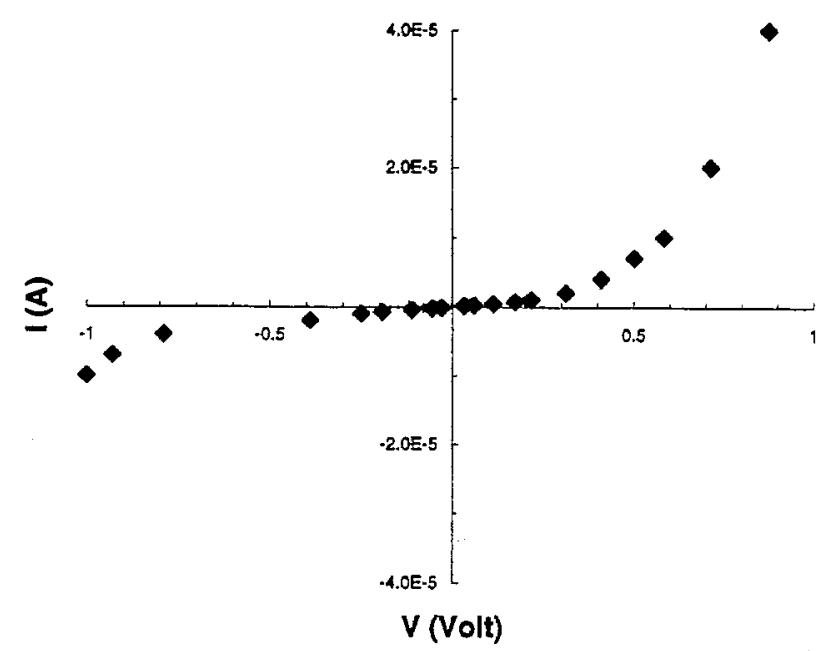

Fig. 4. I-V characteristic of In/composite/Pt sandwich junction (second system, $\sigma \approx 1 \mathrm{~S} / \mathrm{cm}$ ).

conductivity $(10-100 \mathrm{~S} / \mathrm{cm})$, no evidence for rectifying behavior has been found even with the low work function metals like In and Al [13].

It is known that the conductivity of the material is important for the construction of a Schottky barrier. High conductivity leads to a narrow depletion width which causes the tunneling currents through the barrier and a bad rectification [10]. Thus, the composite films with lower conductivities $(0.01 \mathrm{~S} /$ $\mathrm{cm})$ were prepared. The $I-V$ behavior of junctions formed with such films gave even better rectifying behaviors. In this case it was clearly observed that the conductivities of the samples are dominant over the insulating layer of the films produced by the second system. This means that there are almost no changes in the rectifying behavior and the diode parameters of the junctions which are produced by both systems.

The forward $I-V$ characteristics of $\mathrm{In} /$ composite/Pt and $\mathrm{Al} /$ composite/Pt junctions have been analyzed by assuming that the Schottky barrier-type devices were constructed and
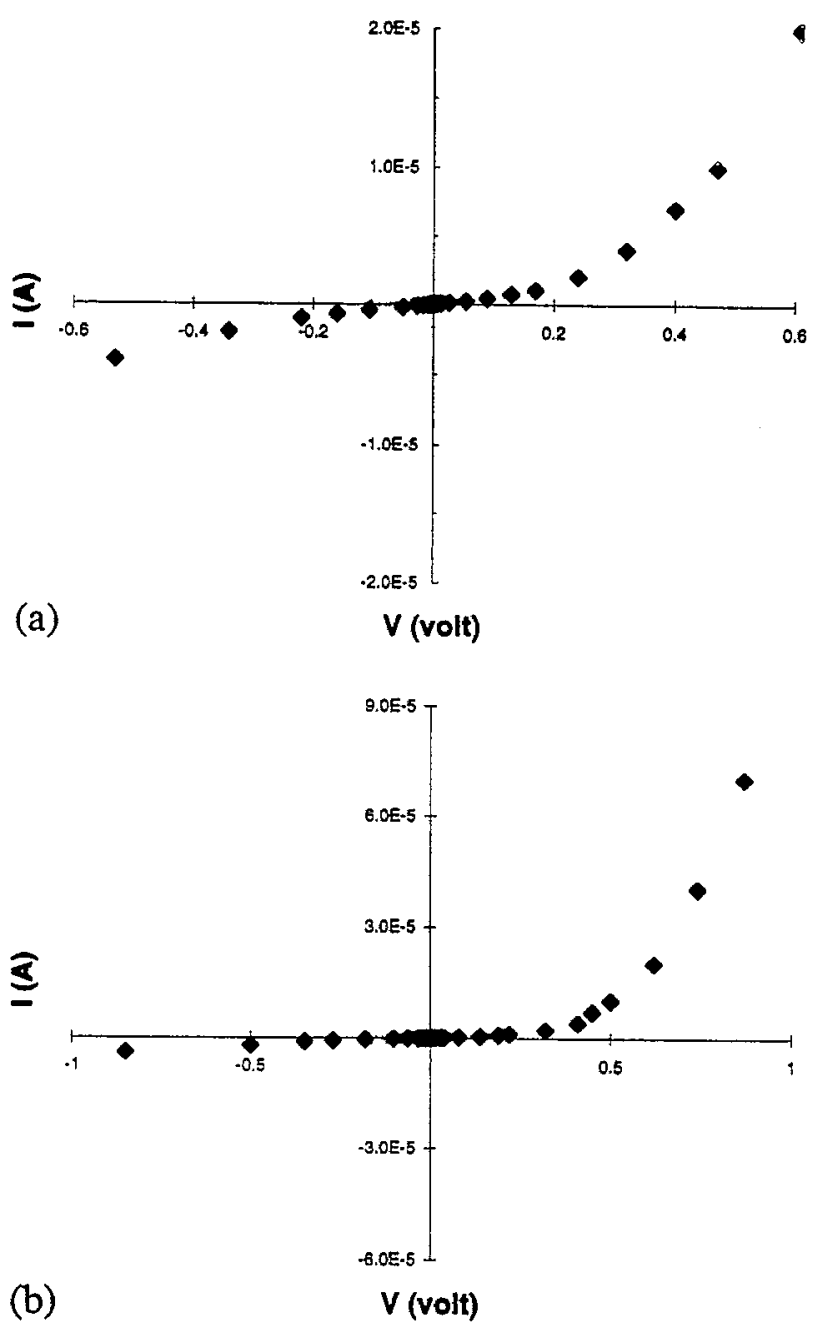

Fig. 5. I-V characteristics of (a) In/composite/Pt and (b) Al/composite/ Pt junctions (second system, $\sigma \approx 0.1 \mathrm{~S} / \mathrm{cm}$ ).

the thermionic emission theory of the Schottky barrier model holds. The $I-V$ relationship is then expressed by [15]

$I=I_{0}[\exp (q V / n k T)-1]$

where $I_{0}$ is the reverse saturation current given by

$I_{\mathrm{o}}=A A^{*} T^{2} \exp \left(-q \varphi_{\mathrm{b}} / k T\right)$

in which $A$ is the contact area, $A^{*}$ is the Richardson constant $\left(120 \mathrm{~A} /\left(\mathrm{K}^{2} \mathrm{~cm}^{2}\right)\right), \varphi_{\mathrm{b}}$ is the junction barrier height and $n$ is the diode ideality factor. At a given temperature the value of $n$ can be obtained from the slope of the semilogarithmic $I-V$ plot and it must be unity for an ideal diode. The typical $\ln (I)-$ $V$ variations of $\mathrm{In} /$ composite/Pt and $\mathrm{Al} /$ composite/Pt Schottky devices for the film conductivity of $0.1 \mathrm{~S} / \mathrm{sm}$ are shown in Fig. 6(a) and (b), respectively. As illustrated in the figures $\ln (I)$ varies linearly with voltage in the voltage range $0.1<V<0.4 \mathrm{~V}$. The deviations from linearity at low bias voltages are due to the shunt resistance and at high voltages $(V>0.4 \mathrm{~V})$ are due to the series resistance effect.

Extrapolation of the linear part of the semilogarithmic plots to zero bias yielded saturation current $I_{\mathrm{o}}$ from which the 


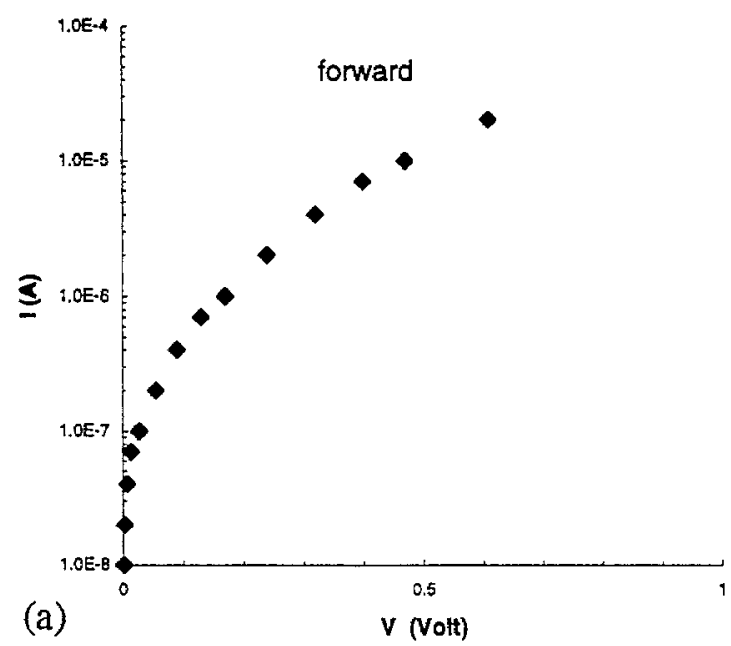

Table 1

Some parameters of In/composite/Pt and Al/composite/Pt Schotky barrier devices

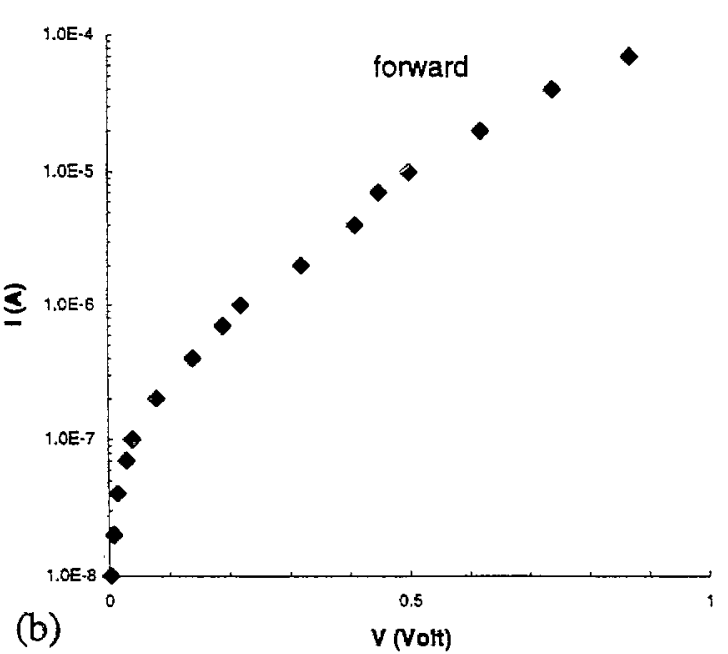

\begin{tabular}{|c|c|c|}
\hline & $\begin{array}{l}\text { In } / \text { composite } / \mathrm{Pt} \\
\text { (first system) }\end{array}$ & $\begin{array}{l}\text { In/composite/Pt } \\
\text { (second system) }\end{array}$ \\
\hline $\begin{array}{l}I_{0}(\mathrm{~A}) \\
n \\
\varphi_{\mathrm{b}}(\mathrm{eV}) \\
\sigma(\mathrm{S} / \mathrm{cm})\end{array}$ & $\begin{array}{l}5 \times 10^{-6} \\
9.6 \\
0.64 \\
\approx 1\end{array}$ & $\begin{array}{l}1.78 \times 10^{-7} \\
5.2 \\
0.72 \\
\approx 1\end{array}$ \\
\hline$\sigma(\mathrm{S} / \mathrm{cm})$ & $\begin{array}{l}\text { In/composite/Pt } \\
\text { (second system) }\end{array}$ & $\begin{array}{l}\mathrm{Al} / \text { composite/Pt } \\
\text { (second system) }\end{array}$ \\
\hline $\begin{array}{l}I_{0}(\mathrm{~A}) \\
n \\
\varphi_{0}(\mathrm{eV}) \\
\sigma(\mathrm{S} / \mathrm{cm})\end{array}$ & $\begin{array}{l}1.25 \times 10^{-7} \\
2.94 \\
0.74 \\
\approx 0.1\end{array}$ & $\begin{array}{l}7.94 \times 10^{-8} \\
2.64 \\
0.75 \\
\approx 0.1\end{array}$ \\
\hline$\sigma(\mathrm{S} / \mathrm{cm})$ & $\begin{array}{l}\text { In/composite/Pt } \\
\text { (second system) }\end{array}$ & $\begin{array}{l}\text { Al/composite/Pt } \\
\text { (second system) }\end{array}$ \\
\hline $\begin{array}{l}I_{0}(\mathrm{~A}) \\
n \\
\varphi_{\mathrm{b}}(\mathrm{eV}) \\
\sigma(\mathrm{S} / \mathrm{cm})\end{array}$ & $\begin{array}{l}2.5 \times 10^{-8} \\
2.3 \\
0.77 \\
\approx 0.01\end{array}$ & $\begin{array}{l}3.1 \times 10^{-7} \\
2.1 \\
0.72 \\
\approx 0.01\end{array}$ \\
\hline$\sigma(\mathrm{S} / \mathrm{cm})$ & $\begin{array}{l}\text { In/composite/ } \mathrm{Pt} \\
\text { (first system) }\end{array}$ & $\begin{array}{l}\mathrm{Al} / \text { composite } / \mathrm{Pt} \\
\text { (first system) }\end{array}$ \\
\hline$I_{0}(\mathrm{~A})$ & $5 \times 10^{-8}$ & $8.3 \times 10^{-7}$ \\
\hline $\begin{array}{l}n \\
\varphi_{\mathrm{b}}(\mathrm{eV})\end{array}$ & $\begin{array}{l}2.3 \\
0.76\end{array}$ & $\begin{array}{l}2.24 \\
0.7\end{array}$ \\
\hline$\sigma(\mathrm{S} / \mathrm{cm})$ & $\approx 0.01$ & $\approx 0.01$ \\
\hline
\end{tabular}

three orders of magnitude lower than the perpendicular resistivity [16].

We have measured the room-temperature $C-V$ dependence

Fig. 6. Semilogarithmic plots of current vs. forward voltage for (a) In/ composite/Pt and (b) Al/composite/Pt junctions (second system, $\sigma \approx$ $0.1 \mathrm{~S} / \mathrm{cm})$

barrier height values were determined using Eq. (2). The diode parameters $\left(n, \varphi_{\mathrm{b}}, I_{\mathrm{o}}\right)$ of different metal/composite/ Pt structures are tabulated in Table 1. The diode ideality factor values indicate that the junctions fabricated with the high conductivity composite films $(1 \mathrm{~S} / \mathrm{cm})$ deviate significantly from ideal Schottky barrier theory and the ones fabricated with lower conductivities have better diode parameters. All the determined values of $n$ are greater than unity. This is probably due to the presence of a thick interfacial layer and/or recombination in the depletion region which will be investigated in detail as a further study. Even though the determination of the barrier heights from $I-V$ characteristics is reliable for low $n \approx 1$ values, the calculated barrier height values are comparable to the ones in the literature $[10,12]$.

In the planar configurations where $\mathrm{Au}$ and low work function metals evaporated on the same surface of the composite films, a non-rectifying behavior was observed regardless of the conductivities of the films. This result is probably due to the difference between the planar and perpendicular conductivities. It was reported that in PPy the parallel resistivity is of the samples prepared by the second system ( $\mathrm{Al} / \mathrm{compo-}$ site/Pt) at $1 \mathrm{MHz}$. The capacitance is found to decrease with increasing reverse bias with an increasing rate at high reverse bias voltages. The $C^{-2}$ versus $V$ plot illustrated in Fig. 7 shows a nonlinear variation which indicates a nonuniform dopant density profile with lower concentration in the bulk than the interface. This nonlinearity may also be attributed to

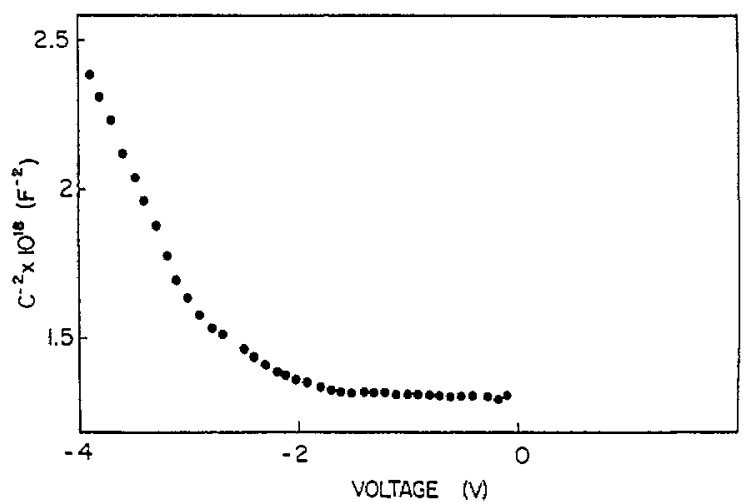

Fig. 7. $C^{-2}-V$ variation of Al/composite/Pt junction (second system, $\sigma \approx 0.1 \mathrm{~S} / \mathrm{cm})$. 
the variation of the effective area of the diode with bias which is the result of the surface irregularities [17] $C^{-2}$ becomes almost independent of the applied bias at around $-1.5 \mathrm{~V}$ which is presumably due to the insulating layer formed at the surface of the conducting polymer prepared by the second system limiting the capacitance at lower reverse bias voltages. Similar $C^{-2}-V$ behavior has been obtained for metal/polymer contacts by melt processing which was attributed to the additional constant capacitance due to the insulating oxide layer at the interface in series with the variable space-charge capacitance of the polymer [18].

\section{Conclusions}

In this work a sample preparation model for a metal/conducting-composite/metal was suggested. Charge transport limitation was observed between low work function metals (In, $\mathrm{Al}$ ), and no charge transport limitation was recorded for high work function metals. It was proved that the rectification becomes better as the conductivity of the composite films decreased. In order to solve the pinhole short problem and obtain films with good surface morphology we produced $\mathrm{PPy} / \mathrm{PIn}$ composite films in which the PPy content was about $80 \%$.

\section{Acknowledgements}

This work is partially supported by Grants DPT $95 \mathrm{~K}$ 120498 and TBAG-1422.

\section{References}

[1] O. Niwa and T. Tamamura, J. Chem. Soc., Chem. Commun., (1984) 817.

[2] B. Zinger and D. Kijel, Synth. Met., 41-43 (1991) 1013.

[3] G.P. Zhang and X. Bi, Synth. Met., $41-43$ (1991) 251.

[4] B. Tieke and W. Gabriel, Polymer, 31 (1990) 20.

[5] Y. Chen, R. Qian, G. Li and Y. Li, Polym. Commun., 32 (1991) 189.

[6] X. Bi and Q. Pie, Synth. Met., 22 (1987) 145.

[7] S. Dogan, U. Akbulut and L. Toppare, Synth. Met., 53 (1992) 29.

[8] F. Selampinar, U. Akbulut, T. Yalcin, S. Suzer and L. Toppare, Synth. Met., 62 (1994) 201.

[9] H.L. Wang, L. Toppare and J.E. Fernandez, Macromolecules, 23 (1990) 1053.

[10] H. Koezuka and S. Etoh, J. Appl. Phys., 54 (1983) 2511.

[11] J.W. Gardener and T.T. Tan, J. Phys.: Condens. Matter, 1 (1989) SB133.

[12] J. Unsworth, Z. Jin, B.A. Lunn and P.C. Innis, Polym. Int., 26 (1991) 245.

[13] O. Inganäs and I. Lundström, Synth. Met., 10 (1984/85) 5.

[14] A. Bozkurt, U. Akbulut and L. Toppare, Synth. Met., 82 (1996) 41.

[15] S.M. Sze, Physics of Semiconductor Devices, Wiley, New York, 1981.

[16] E. Garcia-Camarero, F. Arjona and C. Guillen, J. Mater. Sci., 25 (1990) 4914.

[17] A.M. Goodmann, J. Appl. Phys., 34 (1963) 329.

[18] M. Sundberg, G. Gustafsson and O. Inganäs, Appl. Phys, Lett., 57 (1990) 733. 